\title{
DIÁLOGOS INTERSEMIÓTICOS: PINTURA, DANÇA E AUDIODESCRIÇÃO VOLTADOS AO ATENDIMENTO DO PÚBLICO SURDOCEGO
}

\author{
Intersemiotic dialogues: painting, dance and audiodescription returned to public \\ surdocego service
}

\author{
Diálogos intersemióticos: pintura, danza y audiodescripción voltados al \\ atendimiento del público surdocego
}

Daniella Forchetti*

\begin{abstract}
Resumo
A Moça de Di é uma performance de dança mediada com audiodescrição. Ela faz parte de uma parceria com a exposição "Sentir prá Ver". O convite veio através da professora e curadora Amanda Tojal. Foi selecionada a pintura Sem título, de Di Cavalcanti (Rio de Janeiro, 18971976), que faz parte de uma das 14 reproduções fotográficas de obras pertencentes à Pinacoteca do Estado de São Paulo. Essa exposição inclui recursos de acessibilidade, entre eles, a audiodescrição mediadora das pinturas, estimulando a exploração e interpretação das obras selecionadas. A performance representando a pintura será mais uma forma de traduzir uma obra de arte por meio da experiência concreta, corporeificando a palavra para o público. Convidamos para essa apresentação uma instituição que atende surdocegos e pessoas com múltiplas deficiências sensoriais da cidade de São Paulo. Foram selecionadas duas surdocegas adultas para participar da pesquisa. Com base nos dados coletados por meio de fotografia e vídeo, foi realizado um estudo de caso. Para a análise dos dados utilizou-se as ferramentas de audiodescrição de dança relatadas por Snyder, fundamentadas no Laban Movement Analysis. Pretendemos demonstrar como a audiodescrição da dança e a vivência da corporeificação da obra pelo surdocego irá somar à compreensão da pintura, colaborando para a fruição da arte.
\end{abstract}

\section{PALAVRAS-CHAVE: Pintura. Dança. Audiodescrição.}

\begin{abstract}
Di"s Girl is a dance performance mediated an audio-description. It is part of a partnership with the exhibition "Sentir prá Ver". The invite came across teacher and curator Amanda Tojal. We was selected as An Untitled, by Di Cavalcanti (Rio de Janeiro, 1897-1976), which is part of the 14 photographic images of works that are part of the Pinacoteca of the State of São Paulo. This exhibition included accessibility features, among them, the mediating audio-description of the paintings, stimulating the exploration and interpretation of the selected works. The performance that represents a concrete expression of artwork for concrete, embodying a word for the public. We invite for the present one institution that work with deafblind and people with multiple sensory disabilities in the city of São Paulo. Two adult deafblinds were selected for the research exercise. Based on the data collected through photography and video, a case study was carried out. For the analysis we used collected data reported by Snyder, of audio description of dance based on the Laban Movement Analysis. We intend to demonstrate how the audio description of

\footnotetext{
* Doutoranda do Programa de Pós-Graduação de Artes da Cena no Instituto de Artes da Universidade Estadual de Campinas (UNICAMP). E-mail: daniforchetti@yahoo.com.br
} 
the dance and the experience of the embodiment of the work by the deafblind will add to the understanding of painting, contributing to the enjoyment of art.

KEYWORDS: Painting. Dance. Audio-description.

\section{Resumen}

La Moza de Di es una actuación de danza mediada con audio-descripción. Ella forma parte de una asociación con la exposición "Sentir prá Ver". La invitación vino a través de la maestra y curadora Amanda Tojal. Se seleccionó la pintura Sin Título, de Di Cavalcanti (Río de Janeiro, 1897-1976), que forma parte de una de las 14 reproducciones fotográficas de obras pertenecientes a la Pinacoteca del Estado de São Paulo. Esta exposición incluye recursos de accesibilidad, entre ellos, la audio-descripción mediadora de las pinturas, estimulando la exploración e interpretación de las obras seleccionadas. El performance representando la pintura será otra forma de traducir una obra de arte por medio de la experiencia concreta, que encarna la palabra para el público. Invitamos a esta presentación a una institución que atiende sordocegos y personas con múltiples deficiencias sensoriales de la ciudad de São Paulo. Se seleccionaron dos sordozgas adultas para participar en la investigación. Con base en los datos recolectados por medio de fotografía y video, se realizó un estudio de caso. Para el análisis de los datos se utilizaron las herramientas de audio-descripción de danza relatadas por Snyder, fundamentadas en el Laban Movement Analysis. Pretendemos demostrar cómo la audio-descripción de la danza y la vivencia de la corporificación de la obra por el sordocego va a sumar a la comprensión de la pintura, colaborando para la fruición del arte.

\section{PALABRAS CLAVE: Pintura. Danza. Audio-descripción.}

\section{INTRODUÇÃO}

“A dançarina se envolve com o tecido e segura com as duas mãos. Gira, gira como uma valsa". (Daniella Forchetti)

O trecho relato faz parte do roteiro de audiodescrição mediadora apresentado durante a performance "A Moça de Di Cavalcanti", no Memorial da Inclusão/ SP. Esse projeto de pesquisa foi realizado para a conclusão do curso de Especialização em Audiodescrição pela Universidade Federal de Juiz de Fora/ MG e em parceria com a exposição "Sentir prá Ver", da minha orientadora e curadora Profa. Dra. Amanda Tojal.

A primeira parte da pesquisa foi realizar uma oficina/performance de dança na exposição "Sentir prá Ver", representando a pintura Sem título de Di Cavalcanti (Rio de Janeiro, 1897-1976). Selecionamos essa obra a fim de criarmos mais uma forma de acessibilidade para compor a exposição, composta por 14 reproduções fotográficas de obras pertencentes da Pinacoteca do Estado de São Paulo. Elas são acompanhadas de outros recursos acessíveis que promovem facilitar a compreensão das obras, como:

\footnotetext{
${ }^{1}$ Trecho do roteiro da audiodescrição mediadora da obra A Moça de Di Cavalcanti. Disponível em: https://www.youtube.com/watch?v=7L3ShUI0c50.
} 
palavras-chave, recursos sonoros, reproduções tridimensionais e bidimensionais e pranchas compostas por figura/fundo em alto-contraste.

A mostra inclui como recurso de acessibilidade a audiodescrição mediadora, isto é, a audiodescrição que estimula a exploração e interpretação das obras selecionadas.

Consideramos a audiodescrição como uma modalidade de tradução intersemiótica que possibilita a transformação das imagens em palavras em eventos culturais, esportivos, pedagógicos e turísticos, permitindo à pessoa cega e com baixa visão uma participação inclusiva e autônoma. Por meio de nosso estudo, pretendemos somar o público surdocego, ampliando a população que já se beneficia do recurso da audiodescrição.

Por meio da representação da pintura através da dança, utiliza-se a audiodescrição como mediação entre a imagem/movimento e a palavra. O primeiro contato se deu por intermédio da performance, tendo o guia-intérprete como mediador, escutando a audiodescrição e a traduzindo para o surdocego. A dança vem compor com esse processo de nomeação, auxiliando a parte comunicacional e expressiva.

A performance representará a corporeificação da palavra para o público surdocego. O termo corporeificação foi baseado no sentido apresentado por Paulo Freire, em seu livro A pedagogia da autonomia, "corporeificação da palavra pelo exemplo".

O roteiro da audiodescrição da performance foi construído pela pesquisadora, que foi também a intérprete-criadora da dança. Sua condição como artista-pesquisadora perpassa por um olhar poético de quem pode incorporar a obra em seu discurso. A narração foi realizada por uma integrante da exposição. O guia-intérprete serviu de mediador entre a audiodescrição da dança e o surdocego.

A pesquisa teve duas surdocegas adultas, selecionadas pelos seus diferentes graus de perdas, sendo uma congênita e outra adquirida. A surdocegueira é uma deficiência única. Diferentemente da somatória da perda visual com a auditiva, apresenta-se com particularidades específicas.

\section{Fundamentação Teórica}

A audiodescrição é um recurso de tecnologia assistiva que transforma a informação visual em verbal. Uma modalidade de tradução intersemiótica no campo da acessibilidade comunicacional, criada para atender as pessoas com deficiência visual. Por meio de pesquisas, pudemos perceber que esse recurso foi se ampliando para pessoas com deficiência intelectual, disléxicas, idosas e analfabetas, contribuindo para sua inclusão cultural, social e escolar.

Motta (2013) apresenta as possibilidades de utilização da audiodescrição no âmbito da inclusão cultural como um recurso de acessibilidade que amplia o entendimento das pessoas com deficiência. A audiodescrição pode ser utilizada em peças de teatro, exposições, musicais, óperas, cinema e espetáculos de dança.

Para que a pessoa com deficiência possa ter entendimento e interprete aquilo que assiste, são audiodescritos o cenário, figurino, personagens com suas expressões faciais e movimentação pelo palco. 
O americano Joel Snyder (2015), um dos precursores de audiodescrição, aponta diretrizes gerais em seu trabalho junto ao American Council of the Blind (ACB), no artigo "Audio description: a path to literacy for all". Baseado nos fundamentos do Laban Movement Analysis (LMA), ele indica diretrizes no trabalho de audiodescrição voltado para danças de forma geral, incluindo o contemporâneo, o balé e performances.

Snyder coloca que o audiodescritor deve começar verificando se os diretores, atores/dançarinos e demais funcionários do teatro sabem o que é audiodescrição, como ela se dá nos espaços culturais, qual sua importância para a acessibilidade do público com deficiência.

Na construção dos roteiros de audiodescrição Snyder (2015) nos sugere procurar transmitir a história da dança, ou o conceito coreográfico, em se tratando de uma coreografia contemporânea. Transmitir uma imagem de forma atraente, ao invés de ficar preso na repetição de uma série de passos. Considerar as descrições dos movimentos interagindo com o tempo coreográfico. Levar em conta o som dos movimentos, efeitos sonoros, partitura musical e o silêncio/pausas, para que o público possa também apreciar. Procurar descobrir qual é a ideia principal que a dança quer comunicar, sua essência. Usar poucas palavras que evocam imagens claras e específicas. Selecionar as informações mais significativas para que o público possa experimentar o movimento, ajudando a compreender a coreografia.

Oliveira (2013), em sua dissertação, como primeira pesquisadora a descrever sobre o tema audiodescrição em dança utilizou o termo poética de audiodescrição como uma arte originada no próprio fazer poético, a partir da obra de partida, a dança. Neste trabalho procurou identificar os elementos da dança partindo da obra Pequetitas coisas entre nós mesmos (2011). Entrou em contato com os participante do grupo com deficiência visual e elaborou o roteiro audiodescrito da cena de dança com a cocriação do grupo.

Um dos precursores do tema audiodescrição de dança no Brasil foi Jorge Rein. Em artigo publicado em 2011 procurou colaborar com o processo de criação de um roteiro de audiodescrição em dança. Segundo suas orientações, a equipe de audiodescrição deve trabalhar em colaboração com o coreógrafo ou diretor artístico; acompanhar o processo de criação coreográfica ou ensaios; o audiodescritor roteirista deve ter afinidade com o tema a ser desenvolvido; utilizar como critério na elaboração do roteiro metáforas ou licenças poéticas para auxiliar na compreensão da obra, sem perder sua essência; procurar preservar as informações sonoras do espetáculo com o mínimo de interferência, em se tratando de uma obra de arte ao vivo, diferente de uma gravação; e, ao final do espetáculo, é importante recolher a devolutiva da recepção da audiodescrição junto às pessoas com deficiência, a fim de poder encontrar os pontos a ser aprimorados.

Já para Snyder (2015), o audiodescritor precisa estudar os padrões de movimento e ter um vocabulário que permita sua expressão verbal de forma clara. Ter uma atenção para as terminologias técnicas, contudo, sua primeira utilização deve acompanhar a descrição real para que os ouvintes que não tenham nenhum conhecimento prévio possam compreender de forma generalizada.

Neste projeto, acreditamos ser importante esclarecer sobre a nomenclatura intérprete-criador. $\mathrm{Na}$ dança pós-moderna e contemporânea tem um corpo cênico participativo no processo de criação, tendo a possibilidade de desenvolver uma 
assinatura própria e se relacionar com diferentes áreas do conhecimento. Seu processo investigativo ocorre em seu próprio corpo, buscando novos movimentos e expressões dramatúrgicas.

Já a nomenclatura dança inclusiva está sendo revista e apresentada como: dança sobre rodas, dança integrada, Danzaterapia, DanceAbility, por exemplo.

Meu primeiro trabalho publicado sobre esse tema foi uma monografia para o Curso de Especialização em Linguagens das Artes pela USP cujo tema é "Dança e inclusão: um projeto de arte-educação" (2007). Nele apresento um pouco mais sobre as descobertas acadêmicas produzidas a partir da prática. A dança por si só é geradora de possibilidades expressivas. A proposta da Dança Inclusiva foi proporcionar a todos os participantes igualdade de condições para desenvolverem seu potencial criativo e de uma forma que todos se sintam fazendo parte do processo. O trabalho de pesquisa teve como base o Projeto Arteiros, que tinha como objetivos principais desenvolver: a consciência corporal, a criatividade, a socialização, a comunicação e a autonomia de todos os participantes. Esse termo também foi utilizado pensando na Lei 13.146, conhecida como Lei Brasileira de Inclusão da Pessoa com Deficiência, referente ao tópico Esporte, Cultura e Lazer: "Assegurar às pessoas com deficiência o direito à prática de educação física escolar, ...garantir a participação das pessoas com deficiência em eventos esportivos e culturais nas esferas municipal, estadual e federal." 2

O projeto de dança inclusiva foi baseado nas experiências da pesquisadora com a Dança Educativa criada por Rudolf Laban. Para ele, essa "nova técnica de dança estimula o domínio do movimento em todos os aspectos corporais e mentais, ampliando-se a dança moderna como uma nova forma de dança cênica e social" (1990, p. 16). A dança coral, ou movimento coral, foi criada por ele para dar "um sentido coletivo, comunitário, festivo, criativo e terapêutico" (apud RENGEL, 2005). Para Laban, adquirimos conhecimento através do corpo, nosso instrumento para pensar, saber e comunicar. Ele criou a nomenclatura esforço para nos mostrar que o movimento começa a ocorrer internamente, através das emoções, sensações e pensamentos. Laban criou formas para que pudéssemos fazer uma análise do movimento. Através de sua metodologia, é possível descrever características do movimento como: qualidade, peso, ritmo, forma, postura, caminho, direção, dimensão, nível espacial, uso do corpo em suas partes e no todo. A princípio essas características favorecem a compreensão/criação da dança, seja por uma pessoa com deficiência ou para público em geral.

Pensando na abordagem multissensorial, possibilitamos com nosso trabalho uma nova forma de intervenção que abre espaço para todos os públicos e possibilita que todos venham com suas famílias e escolas e sintam-se acolhidos, procurando eliminar qualquer forma de barreira (física, sensorial, comunicacional e atitudinal) para permitir o acesso de todos.

\section{Contextualização metodológica}

Realizamos um estudo de caso, de natureza exploratória, sobre o tema audiodescrição de dança, representando uma pintura para o público surdocego. Os objetivos desse estudo foram: fazer um delineamento mais adequado para a investigação

\footnotetext{
${ }^{2}$ Disponível em: https://www.pessoacomdeficiencia.gov.br/app/node/518
} 
de um fenômeno contemporâneo dentro de seu contexto real; preservar as características do objeto estudado; descrever o contexto de uma determinada investigação; formular hipóteses e desenvolver teorias (GIL, 2002).

Utilizando uma abordagem qualitativa, foi possível investigar e fazer parte como objeto da pesquisa. Também houve uma maior proximidade em relação aos fenômenos estudados, já que a pesquisadora foi a intérprete-criadora que representou a obra de Di Cavalcanti, pintura Sem título, selecionada para a pesquisa. Também foi feito o roteiro da audiodescrição e a análise dos vídeos gravados de pesquisa.

Utilizamos os seguintes instrumentos para a documentação da pesquisa:

- gravação da performance com audiodescrição;

- gravação de duas surdocegas adultas com seus respectivos guias-intérpretes no momento em que assistem à performance;

- gravação do momento que interagem tocando na intérprete-criadora;

- gravação do momento em que cada surdocega irá interpretar sua compreensão da obra através do movimento da dança;

- fotografia dos momentos em que as participantes surdocegas estiveram interagindo na exposição com as obras acessíveis.

Foram indicadas duas mulheres surdocegas como idade aproximada de 25 e outra com 60 anos, que se utilizam de formas de comunicação diferentes para representarem um público mais diverso. Elas fazem parte de uma instituição ${ }^{3}$ voltada ao atendimento de pessoas surdocegas e com múltiplas deficiências sensoriais, da cidade de São Paulo, Brasil.

Essa experiência foi realizada com apenas uma obra das 14 reproduções que compõem a exposição "Sentir prá Ver", apresentada de 8 de abril a 26 de junho de 2015, sediada no Memorial da Inclusão, em São Paulo, Brasil.

\section{Seleção da Obra}

Foi selecionada a obra de Di Cavalcanti para a realização da pesquisa pela facilidade que a pesquisadora teria de representar um personagem, construindo uma narrativa baseada na imagem pintada do quadro, com os elementos cênicos apresentados, buscando ser o mais fidedigna com a obra.

\section{Figura 1}

\footnotetext{
${ }^{3}$ Grupo Brasil de Apoio ao Surdocego e ao Múltiplo Deficiente Sensorial, sendo representante do grupo no dia a professora Alice Floter.
} 


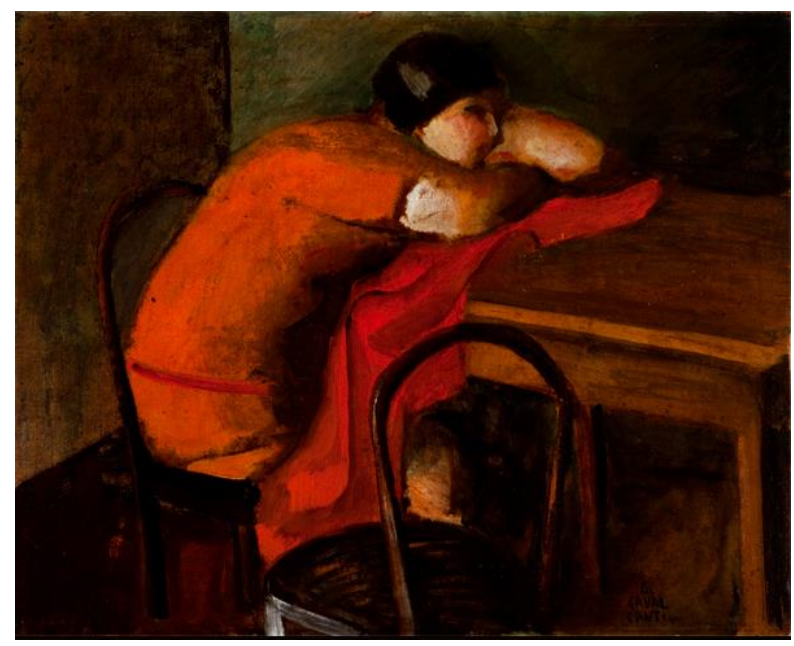

Figura 1: Sem título, óleo s/ papelão, Di Cavalcanti, sem data ${ }^{4}$

Descrição da Imagem: Pintura de uma jovem mulher morena de perfil, cabelos curtos pretos, olhos pretos. Usa vestido laranja com mangas curtas, cinto vermelho. Está sentada em uma cadeira de madeira com a cabeça apoiada sobre o antebraço esquerdo, braços cruzados, debruçada sobre uma mesa de madeira com uma toalha vermelha caindo sobre seu colo. Do lado direito uma cadeira de madeira vazia. Uma luz incide do canto esquerdo sobre o dorso da mulher. No fundo, paredes verde escuro até o tom marrom, chão marrom escuro.

\section{Apresentação, Análise E Discussão Dos Resultados}

Nessa etapa, partimos para a apresentação do roteiro da audiodescrição da dança. É importante lembrar que já existia uma audiodescrição mediadora do quadro de Di Cavalcanti, que faz parte da exposição "Sentir prá Ver". No entanto, foi realizada a construção de um novo roteiro da audiodescrição de dança representando a obra com base em um contexto mais geral, que fez parte da corporeificação da pintura em movimento.

Para auxiliar na análise dos dados utilizamos as ferramentas de audiodescrição de dança descritas por Snyder (2015), fundamentadas no Laban Movement Analysis (LMA). Procurou-se observar:

- Apresentação da descrição do figurino, aparência do dançarino, os elementos cênicos e adereços;

- Que elementos compõem o tema coreográfico;

- Quais atitudes do corpo do dançarino transmitem a ideia do personagem;

- Quais são as qualidades de movimento mais significativos demonstram expressividade/ dinâmica;

- Como a experiência sensorial tátil colaborou para a compreensão da audiodescrição da dança;

- Como a experiência de dançar com seus próprios corpos colaborou para a compreensão da criação da imagem da pintura, obra de Di Cavalcanti.

\footnotetext{
${ }^{4}$ Fonte: http://www.sentirpraver.com.br/obra_dicavalcante.html
} 
Por meio desses instrumentos de análise pretendeu-se compreender como a audiodescrição da dança fazia o papel de mediação no acesso à fruição da arte, no caso de o surdocego, entrar em contato com a pintura de Di Cavalcanti.

Para a análise dos dados foi utilizando os apontamentos sugeridos por Snyder. Devemos iniciar descrevendo o figurino e a aparência dos dançarinos, os elementos cênicos e os adereços. Ele coloca que é importante considerar as descrições dos movimentos interagindo com o tempo coreográfico.

Iniciamos com a audiodescrição da intérprete-criadora que estará dançando a obra e do cenário:

Intérprete-criadora: mulher de pele clara, cabelos castanhos presos. Usa vestido laranja com mangas curtas, decote em vê com gola de renda, cinto vermelho e está descalça.

Cenário: Uma mesa e duas cadeiras de madeira iluminadas por focos de luz branca, sobre um carpete cinza. No fundo, imagem de muitos rostos de representantes dos direitos das pessoas com deficiência.

Figura 2

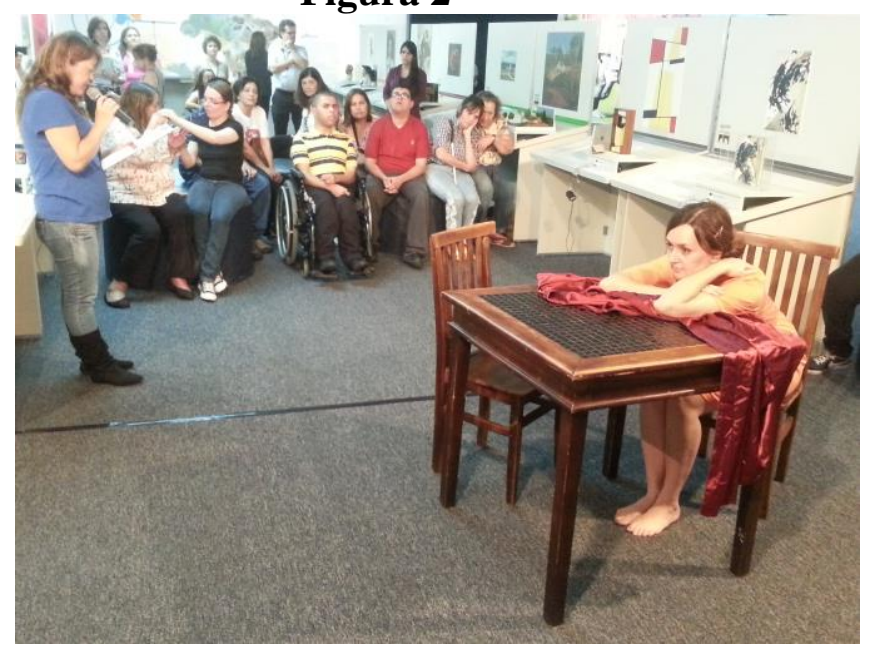

Figura 2: Apresentação na exposição “Sentir prá Ver”. Fonte: Memorial da Inclusão.

Link da apresentação: https://youtu.be/7L3ShUI0c50

Descrição da Foto: No canto direito uma dançarina de perfil, pele clara, cabelos castanhos presos, usa um vestido laranja, sentada numa cadeira de madeira, debruçada sobre uma mesa com uma toalha vermelha. Ao lado uma cadeira vazia. No fundo a 
plateia e parte da exposição. No canto esquerdo, de pé, audiodescritora fala no microfone.

No segundo momento, após a apresentação da performance, a pesquisadora foi em direção aos surdocegos, levando-os um por vez para reconhecerem o cenário. Após isso, a pessoa surdocega experimenta tocar a intérprete-criadora, que corporifica a forma da obra de arte acessível. Nesse momento, a seu lado, o guia-intérprete acompanha o percurso. Também foi feito o processo de nomeação.

Para Snyder (2015), sempre que possível é bom incluir uma experiência sensorial tátil nas apresentações de dança/performance. Pode ser antes da apresentação, ou depois, nos bastidores, sempre que puder tocar os corpos dos dançarinos, os adereços e as fantasias.

No terceiro momento, o surdocego representou a obra utilizando-se do movimento para criar sua interpretação da audiodescrição da performance e o toque na corporeificação da pintura feita pela intérprete.

No caso de nosso estudo, traduzimos para o contexto como o intérprete-criador exemplificando a obra de arte para o surdocego, de maneira tridimensional e realista. E o surdocego, de maneira autônoma, pode criar sua própria imagem mental da obra através do toque e da audiodescrição combinados.

Para a análise dos dados, foram utilizadas as categorias de "ação básica de esforço" criadas por Laban (1990) e sistematizadas no Dicionário Laban, escrito por Rengel (2005). Serão elencadas as oito ações para sistematizar o material documentado em vídeo e o passo a passo apresentado nas fotos. Para auxiliar na análise dos dados utilizamos as ferramentas de audiodescrição de dança descritas por Snyder, fundamentas no Laban Movement Analysis (LMA).

No quarto momento, dentro do espaço de exposição, a surdocega tocou a maquete da obra, a reprodução em relevo, a prancha de alto-contraste (figura/fundo nas cores preto e amarelo) e o texto com legendas da obra em braille.

Segundo Tojal (2007), a percepção multissensorial aplicada às ações educativas em museus e espaços expositivos devem priorizar experiências concretas e da aproximação dos visitantes com o meio ambiente.

No momento em que foram apresentadas à exposição, tocaram primeiro a maquete da obra. Ambas as surdocegas reconheceram as semelhanças entre a intérpretecriadora e a miniatura da personagem, como também os elementos cênicos. Para a primeira, S., a reprodução em relevo se mostrou mais interessante e com detalhes do que a prancha de contraste. Já a segunda, L., interessou-se mais pela prancha de altocontraste do que a reprodução em relevo, já que ela tem baixa-visão enquanto S. é cega.

\section{CONSIDERAÇÕES FINAIS}

Esse projeto em parceria com a exposição "Sentir prá Ver" teve o objetivo de proporcionar às pessoas surdocegas o direito de fazerem parte de todo o processo de apreciação de uma obra, observando suas singularidades. Incluir o guia-intérprete é

\footnotetext{
5 Ação básica de esforço é a "ação na qual fica evidente uma atitude do agente perante os fatores de movimento espaço, peso e tempo (v. atitude interna)”. (RENGEL, 2005, p. 23)
} 
valorizar a forma como o surdocego se comunica e possibilitar mais um recurso informativo e poético. Ao convidarmos o surdocego a expressar o "quadro vivo" que representa a obra, abrimos a possibilidade para que ele possa fazer sua própria interpretação do tema, "corporeificando a obra pelo exemplo". Ao visitar a exposição, ele já estará imerso na obra, partindo de um lugar de apreciador que poderá usufruir melhor de todos os recursos acessíveis dessa experiência sensorial tátil. Poderá fazer suas associações e nos mostrar inclusive o que mais lhe é conveniente, com os recursos sensoriais de apoio, suas preferências por uma maquete, uma prancha em relevo ou de contraste. Isso só é possível quando ampliamos e diversificamos a oferta de experiências e não simplesmente apresentamos a audiodescrição da obra, que para muitos pode ser suficiente, mas, ainda assim, alguns ficariam de fora.

Como um estudo de caso, ele é apenas um primeiro passo em direção à disseminação de uma ideia, propiciar ações que ampliem de forma significativa as possibilidades de apreciação da arte. Pensar num formato universal é pensar em todos, e todos juntos poderemos compartilhar a arte.

\section{REFERÊNCIAS}

AMARANTE, P.; LIMA, R. (coord.) Nada sobre nós sem nós. Rio de Janeiro: Laps, 2009. Disponível em: $\leq$ http://www.cultura.gov.br/documents/10913/43697/nada-sobrenos-sem-nos.pdf/1546353f-7bc7-4ac4-81e9-301b646c14e8>. Acesso em: <30 ago. 2015>.

BOVE, M.; RIGGIO, M. La comunicación pre-linguistica com enfasis en descapacidad severa. Resumenes de la XI Conferência Internacional para a Educação dos Surdocegos, IADB, Córdoba, Argentina, 1996.

FERREIRA, A. Intérprete-criador na dança contemporânea: um corpo polissêmico e coautor. Anais do II Congresso de Pesquisa em Dança - ANDA, jul. 2012. Anais eletrônicos... Disponível em: <http://www.portalanda.org.br/anaisarquivos/6-20123.pdf $>$. Acesso em: $<12$ out. 2015>.

FORCHETTI, D. DiDanDa: dança experimental. In: III Fórum Virtual Ibero Latino Americano sobre Surdocegueira e Múltipla Deficiência Sensorial, UFAL, 2015, Alagoas. Anais eletrônicos... Alagoas: UFAL 2015. Disponível em: $<$ http://grupobrasilsurdocegueira.org/mod/folder/view.php?id=75>. Acesso em: $<28$ abr. 2015>.

A história de Iago: o menino guerreiro no mundo da comunicação alternativa. Dissertação (Mestrado em Distúrbios da Comunicação). PUC/SP, São Paulo, 2000.

Dança e inclusão: uma proposta em arte-educação, 2013. Disponível em:

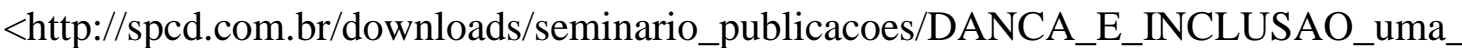
proposta_de_projeto_em_arte-educacao_DanielaForchetti_OK.pdf $>$. Acesso em: 29 abr. 2015. 
Projeto Arteiros: uma proposta de dança inclusiva. São Paulo: USP, 2007. I Simpósio Internacional de Estudos sobre a Deficiência - SEDPcD/Diversitas/USP Legal - São Paulo, junho/2013. Anais... Disponível em: <http://www.memorialdainclusao.sp. gov.br/br/ebook/Textos/Daniella_Forchetti.pdf $>$. Acesso em: 10 set. 2015.

Vencendo as barreiras da comunicação. Um retrato da comunicação alternativa no Brasil, Vol. II, Programa de Pós-Graduação em Educação, p. 148-152, UERJ, 2007.

FREIRE, P. Pedagogia da autonomia: saberes necessários à prática educativa. 25. ed. São Paulo: Paz e Terra, 1987.

FUX, M. Depois da queda...dançaterapia. São Paulo: Summus, 2005.

GIL, A. C. Como elaborar projetos de pesquisa. São Paulo: Atlas, 2002.

LABAN, R. Dança educativa moderna. Tradução e ampliação Lisa Ullmann. São Paulo: Ícone, 1990.

MOTTA, L.M.V. Audiodescrição: recurso de acessibilidade para a inclusão cultural das pessoas com deficiência visual. 2013. Disponível em:

$<$ http://vercompalavras.com.br/pdf/artigo-audiodescricao-recurso-de-acessibilidade.

Pdf>. Acesso em: 29 abr. 2015.

MOTTA, L.M.V.; ROMEU FILHO, P. (Orgs.) Audiodescrição: transformando imagens em palavras. São Paulo: Secretaria de Estado dos Direitos da Pessoa com Deficiência, 2010.

NEVES, R.M.S. Dança é para todos. Reflexões sobre Laban, o mestre do movimento. São Paulo: Summus, 2006.

OLIVEIRA, A.C.S. Por uma poética da audiodescrição em dança: uma proposta para a cena da obra Pequetitas coisas entre nós mesmos. Dissertação (Mestrado em Dança). Universidade Federal da Bahia, Escola de Dança, Salvador, 2013. Disponível em:<https://repositorio.ufba.br/ri/bitstream/ri/12421/1/DISSERTA\%C3\%87\%C3\%83O \%20Ana\%20Clara.pdf $>$. Acesso em: 30 abr. 2015.

REIN, J. A Audiodescrição entra na dança. Revista Brasileira de Tradução Visual. Vol. 8, n. 8, 2011. Disponível em: <http://www.rbtv.associadosdainclusao.com.br/ index.php/ principal/ article/ view Article/109>. Acesso em: 30 abr. 2015.

RENGEL, L. Dicionário Laban. 2. ed. São Paulo: Annablume, 2005.

VAN DJCK, J. Movimento e comunicação com crianças rubeólicas. Tradução: Dalva Rosa. Conferência pronunciada na Reunião Geral Anual - ONCE, Espanha, maio, 1968. 
SNYDER, J. Audio description: a path to literacy for all. Disponível em: $<$ https://www.kennedy-center.org/education/vsa/resources/SnyderJoelAD-Apathto Literacy. Pdf>. Acesso em: 30 ago. 2015.

TOJAL, A.P.da.F. Museu de arte e público especial. Dissertação (Mestrado em Arte). Escola de Comunicações e Artes, Universidade de São Paulo, São Paulo,1999. Cap. I.

Recebido em: 24/10/2019

Aprovado em: 19/12/2019 